Review

\title{
Circulating MicroRNAs: Potential Biomarkers for Cancer
}

\section{De-Cai Yu ${ }^{1,2}$, Qing-Guo Li ${ }^{1}$, Xi-Wei Ding ${ }^{1}$ and Yi-Tao Ding ${ }^{1,2, *}$}

1 Institute of Hepatobiliary Surgery, Nanjing University, Nanjing, Jiangsu, China;

E-Mails: dryudecai@ hotmail.com (D.-C.Y.); lqg0235062@163.com (Q.-G.L.); dxw0008@sina.com (X.-W.D.)

2 Department of Hepatobiliary Surgery, the Affiliated Drum Tower Hospital, School of Medicine, Nanjing University, Nanjing, Jiangsu, China

* Author to whom correspondence should be addressed; E-Mail: drdingyitao@sina.com; Tel.: +86-25-83304616 (ext. 66866); Fax: +86-25-83317016.

Received: 21 December 2010; in revised form: 10 February 2011 / Accepted: 10 March 2011 / Published: 22 March 2011

\begin{abstract}
Cancer is the leading cause of death in the world. Development of minimally invasive biomarkers for early detection of cancer is urgently needed to reduce high morbidity and mortality associated with malignancy. MicroRNAs (miRNAs) are small regulatory RNAs that modulate the activity of specific mRNA targets and play important roles in a wide range of physiologic and pathologic processes. Recently, miRNAs were found to be dysregulated in a variety of diseases including cancer. Emerging evidence suggests that miRNAs are involved in tumor initiation and progression. Together, the different expression profiles of miRNAs in cancer, and the stability of circulating miRNAs, make them new potentially clinical biomarkers for cancer diagnosis, classification, therapeutic decisions, and prognosis.
\end{abstract}

Keywords: circulation; microrna; neoplasm; biomarkers

\section{Introduction}

Cancers are often diagnosed at a late stage with concomitant poor prognosis. The development of minimally invasive tests for the detection and monitoring of common epithelial malignancies could greatly reduce the worldwide health burden of cancer [1]. As the blood is easily accessible and taking a sample is lowly invasive, testable biomarkers found in blood would be especially useful. Conventional 
strategies for blood-based biomarker discovery (e.g., circulating proteins, DNA, mRNA) have shown promise, but their clinical use has been limited due to lack of sufficient sensitivity, specificity, and stability [1]. New approaches that can complement and improve on current strategies for cancer detection are urgently needed.

MiRNAs are small (typically $\sim 22 \mathrm{nt}$ in size) regulatory RNA molecules that modulate the activity of specific mRNA targets and play important roles in a wide range of physiologic and pathologic processes [2]. Altered miRNA expression has been reported in various cancers, and the expression patterns of miRNAs in human cancer appear to be tissue-specific [3]. MiRNAs have shown great potential as tissue-based markers for cancer definition. Recently, the findings that human blood contains stably expressed miRNAs have revealed a great potential of circulating miRNA signature as disease fingerprints to predict survival [4]. Due to their size, abundance, tissue specificity, and relative stability in circulation, miRNAs hold promise as unique accessible biomarkers to detect and monitor cancer.

\section{MiRNA Function}

MiRNAs are small ( 22 nt), endogenous, single-stranded, non-coding regulatory RNA molecules. MiRNAs genes often cluster in the genome and are transcribed by RNA polymerase II to form pri-miRNAs in the nucleus. Pri-miRNAs then undergo processing by two cellular nucleases, Drosha and Dicer, to generate mature miRNAs. In animals, miRNAs mostly bind to complementary sequences in the 3' untranslated region (UTR) of their target mRNAs and negatively regulate gene expression either by translational repression or degradation of the mRNA transcript. MiRBase (Release 14.0), the central database for miRNAs, lists 15,172 entries with 1048 human miRNAs until now [5]. Many miRNAs are well conserved across all species, suggesting a crucial role. Studies have shown that miRNAs are involved in various biologic processes and pathways such as cell proliferation, differentiation, apoptosis, metabolism, and tissue morphogenesis. Recent data suggest a direct link between miRNAs and disease, and miRNA expression signatures are associated with various types of cancer. In addition, the discovery that miRNAs are often expressed in a very tissue-specific manner during development is also suggestive of a crucial role of miRNAs in specifying and maintaining tissue identity.

\section{Specific Expression of MiRNAs in Cancer}

It is now recognized that miRNAs are frequently dysregulated in various cancers [6]. A number of miRNAs were shown to be located in fragile regions of the human genome that are associated with cancer [7]. Functional studies indicate that miRNAs have both tumor suppressive and oncogenic potential in human cancer [8]. Under-expressed miRNAs such as let-7 in lung cancer and miR-15/16 in leukemia are tumor suppressor genes, suppressing Ras and BCL2, respectively [9,10]. Over-expressed miRNAs, such as mir-21 and the cluster mir-17-92, are oncogenes, targeting tumor suppressors PTEN and E2F1 in solid and hematologic malignancies, respectively [11]. Furthermore, dysregulated miRNAs have been shown to play a crucial role in tumor initiation, progression, and metastasis, and are often associated with diagnosis, prognosis, and response to therapy [12-14]. With the development of technologies to detect the expression levels of hundreds of miRNAs at a time and the clear role of 
miRNAs in cancers, groups began looking at miRNA profiles of different cancers. Lu [15] developed a method for bead-based miRNA profiling. Employing this technique on twenty different cancers, they found that each cancer had a specific miRNA profile and that most poorly differentiated tumors could be classified to their tissues of origin based on their miRNA expression levels. Furthermore, miRNA expression differentiates histology and predicts survival and relapse of lung cancer $[9,16,17]$.

\section{Circulating MiRNAs: Stable RNA Molecules}

Circulating miRNAs are not only abundant in blood, but also very stable, which are important prerequisites as clinical biomarkers. MiRNAs are well resistant to plasma RNases. Mitchell [18] compared the stability of endogenous miRNAs with synthetic miRNAs without homologous sequences into human plasma. The levels of endogenous miRNAs were not significantly altered, while synthetic miRNAs rapidly degraded when added directly to plasma. Chen [19] treated miRNAs with RNase A digestion, while 18s rRNA, 28s rRNA, GAPDH, $\beta$-actin, and U6 were used as controls. Surprisingly, more than half of the miRNAs remained intact after $3 \mathrm{~h}$ of exposure to RNase A. In contrast, all controls were rapidly degraded by RNase A. Furthermore, miRNAs remain stable after being subjected to harsh conditions including boiling, low/high $\mathrm{pH}$, extended storage, freeze-thaw cycles and so on. MiRNAs also have unusually high stability in formalin-fixed tissues [20]. The mechanism of resistance of miRNAs to RNase requires further studies. Of note, measurements obtained from plasma or serum were strongly correlated, indicating that both serum and plasma samples will be suitable for investigations of miRNAs as blood-based biomarkers [18].

In sum, miRNAs in the circulation are relatively stable, very accessible, low invasive, and easily testable biomarkers.

\section{The Origin and Function of Circulating MiRNAs in Tumors}

Circulating miRNAs in the blood of cancer patients could play the same important roles as miRNAs in tissues. However, the secretory mechanism and biological function of extracellular miRNAs remain unclear. Mitchell [18] used a mouse xenograft model where a human prostate cancer cell line was implanted into mice to show that there were tumor-derived miRNAs circulating in blood. The plasma miR-184 levels were 10-fold reduced after the surgical removal of tumor, which further suggested that miRNAs originated from the primary tumor [21]. Furthermore, employing Solexa deep sequencing, Chen identified specific expression patterns of serum miRNAs for lung cancer and colorectal cancer, providing evidence that both of these two cancers had specific serum-miRNA profiles. These reports clearly show that cancers affect miRNA levels in the circulation, although it is still unclear how tumor miRNAs come into the circulation.

Tumor miRNAs may be present as a result of tumor cells dying and getting lysed or tumor cells releasing exosomes that contain miRNAs. Tumor-derived exosomes are small membrane vesicles of endocytic origin released by the tumor, which may play important roles in cell-cell communication [22]. Ceramide, whose biosynthesis is regulated by neutral sphingomyelinase 2 (nSMase2), triggers secretion of small membrane vesicles called exosomes [23]. Furthermore, Rabinowits [24] demonstrated that there was a close correlation between circulating miRNAs of tumor-derived 
exosomes and tumor miRNAs in lung adenocarcinoma. Thus, exosomes could be an important source of miRNA in the circulation.

\section{Circulating MiRNAs: the Biomarkers of Tumors}

Through various techniques, numerous groups have shown that different cancer types have distinct miRNA profiles, summarized in Table 1. These findings suggest that circulating miRNAs have potential use as novel biomarkers for diagnosis and prognosis, and may prove useful information in clinical management during the peri-operative period.

Mitchell et al. [18] investigated that miRNAs originating from human prostate cancer xenografts enter into the circulation, are readily measured in plasma, and can robustly distinguish xenografted mice from controls. Their concepts extended to cancer in humans, where circulating levels of miR-141 (a miRNA expressed in prostate cancer) can distinguish patients with prostate cancer from healthy controls. Furthermore, the elevated serum levels of miR-200a and miR-200b in most patients with pancreatic cancer could have diagnostic utility [25]. The plasma concentrations of miRNAs (miR-17-5p, miR-21, miR-106a, miR-106b) in gastric cancer [2,26], and miR-184 in squamous cell carcinoma patients [18], and miR-195 and let-7a in breast cancer [27], were significantly higher than controls, and significantly reduced further after the surgical removal of tumor. Otherwise, the relative amount of miR-92a in the plasma from hepatocellular carcinoma (HCC) patients was decreased compared with that from healthy donors, but was elevated after surgical treatment [28] .The reduction or elevation of plasma miRNA levels after the surgical removal of tumor further confirmed the correlation between miRNA and the primary tumors. Furthermore, Heneghan [27] found that specific circulating miRNAs correlated with certain pathological variables, namely nodal status and estrogen receptor status.

Calin et al. [29] were the first to show that their miRNA microarray could differentiate between B cell chronic lymphocyte leukemia (CLL) cells and normal cells. Furthermore, they classified CLL samples into two different groups based on their miRNA profiles, and these profiles corresponded to high or low levels of a protein that is associated with a positive prognosis at low levels. The patients with diffuse large B cell lymphoma (DLBCL) had high serum levels of miR-21, which was associated with improved relapse-free survival [30]. This result is consistent with their previous findings in biopsy material from a different cohort of DLBCL patients, where high tumor miR-21 expression was also associated with a more favorable clinical outcome. Most recently, Leidinger [31] screened and filtered 51 differentially regulated miRNAs in blood cells of melanoma patients. With a subset of 16 significantly deregulated miRNAs, the classification accuracy, specificity, and sensitivity reached $97.4 \%, 95 \%$, and $98.9 \%$ by supervised analysis. $\mathrm{Hu}$ [32] also found that the miRNA signature from the serum may predict overall survival of non-small cell lung cancer (NSCLC). Eleven serum miRNAs were found to be altered more than five-fold by Solexa sequencing between longer-survival and shorter-survival groups, and levels of four miRNAs (i.e., miR-486, miR-30d, miR-1 and miR-499) were significantly associated with overall survival. 
Table 1. Circulating miRNAs as biomarkers of tumor.

\begin{tabular}{|c|c|c|c|}
\hline Tumor Type & MicroRNAs & Significance & References \\
\hline Breast cancer & $\begin{array}{l}\text { miR-195 and let-7a; } \\
\text { miRNA-21, 106a, 126, } \\
155,199 \mathrm{a} \text { and } 335\end{array}$ & $\begin{array}{l}\text { Correlated with nodal status } \\
\text { and estrogen receptor status, } \\
\text { and decreased postoperatively }\end{array}$ & {$[27,33]$} \\
\hline $\mathrm{CRC}$ & $\begin{array}{l}\text { miR-92; miR-29a and } \\
\text { miR-92a }\end{array}$ & $\begin{array}{l}\text { Diagnosis with } 70 \% \\
\text { specificity and } 89 \% \\
\text { sensitivity; early detection of } \\
\text { CRC }\end{array}$ & {$[34,35]$} \\
\hline DLBCL & $\operatorname{miR}-21$ & Relapse-free survival & [30] \\
\hline Gastric cancer & $\begin{array}{l}\text { miR-17-5p, miR-21, } \\
\text { miR-106a, miR-106b, } \\
\text { let-7a; miR-1, miR-20a, } \\
\text { miR-27a, miR-34 and } \\
\text { miR-423-5p }\end{array}$ & $\begin{array}{l}\text { Up or down-regulated; } \\
\text { Correlated to tumor stage }\end{array}$ & {$[26,36]$} \\
\hline $\mathrm{HCC}$ & $\begin{array}{l}\text { miR-92a; miR-500; } \\
\text { miR-25, miR-375, and } \\
\text { let-7f }\end{array}$ & $\begin{array}{l}\text { Down-regulated, up-regulated } \\
\text { after surgical treatment, and } \\
\text { diagnosis }\end{array}$ & {$[28,37,38]$} \\
\hline Leukemia & $\begin{array}{l}\mathrm{miR}-92 \mathrm{a} / \mathrm{miR}-638 \\
\mathrm{miR}-29 \mathrm{a},-181 \mathrm{a}, \text { and }-221\end{array}$ & Diagnosis and treatment & {$[39,40]$} \\
\hline Melanoma & gene profiles & $\begin{array}{l}21 \text { miRNAs down-regulated } \\
\text { /30 miRNAs up-regulated }\end{array}$ & {$[31]$} \\
\hline MM & miR-193b-365 & Up-regulated & [41] \\
\hline NSCLC & $\begin{array}{l}\text { miR-25 and miR-223; } \\
\text { exosomal miRNA; } \\
\text { miR-486, miR-30d, miR-1 } \\
\text { and miR-499 }\end{array}$ & $\begin{array}{l}\text { Up-regulated; screening test; } \\
\text { overall survival }\end{array}$ & {$[19,24,32]$} \\
\hline Oral cancer & miR-31; miR-184 & $\begin{array}{l}\text { Up-regulated, and } \\
\text { down-regulated after surgical } \\
\text { resection.; diagnosis }\end{array}$ & {$[21,42]$} \\
\hline Ovarian cancer & $\begin{array}{l}\text { miRNAs-21, 92, 93, } 126 \\
\text { and 29a; MiRNAs-155, } \\
127 \text { and } 99 b\end{array}$ & $\begin{array}{l}\text { Up-regulated, and related } \\
\text { with pre-operative CA-125; } \\
\text { down-regulated; exosomes }\end{array}$ & {$[43-45]$} \\
\hline Pancreatic cancer & $\begin{array}{l}\text { miR-21, miR-210, } \\
\text { miR-155, and miR-196a }\end{array}$ & Diagnosis & {$[25,46-48]$} \\
\hline Prostate cancer & miR-141 & Diagnosis & {$[18]$} \\
\hline ESCC & $\begin{array}{l}\text { miR-10a, miR-22, } \\
\text { miR-100, miR-148b, } \\
\text { miR-223, miR-133a, and } \\
\text { miR-127-3p }\end{array}$ & Up-regulated & [49] \\
\hline Rhabdomyosarcoma & miR-206 & Up-regulated & {$[50]$} \\
\hline
\end{tabular}

CRC: colorectal carcinoma; DLBCL: diffuse large B cell lymphoma; HCC: hepatocellular carcinoma; MM: Multiple myeloma; ESCC: esophageal squamous cell carcinoma. 


\section{Perspectives}

Together, these results indicate that circulating miRNAs have many characteristics of ideal biomarkers, most notably their inherent stability and resilience. Firstly, miRNA expression is frequently dysregulated in cancer [3,6]. Secondly, expression patterns of miRNAs in human cancer appear to be tissue-specific [15]. Thirdly, miRNAs have unusually high stability [4]. The expression of specific circulating miRNAs is a good surrogate of tumor miRNA expression and initiates a new paradigm that will be useful not only for early diagnosis but also for prognostic and therapeutic decisions [51].

Furthermore, a lot of challenges regarding miRNAs in sera need to be confronted. Firstly, the specificity of miRNAs: one miRNA can distinguish different cancers which have the same serum miRNA, e.g., miR-21 in DLBCL and pancreatic cancer. Secondly, the standardization of miRNAs: the preparation of serum/plasma will need be standardized in order to generalize findings from different patients, groups, or labs. Thirdly, the quantification of miRNAs: what will be used as a standard for qRT-PCR for measuring circulating miRNAs (e.g., as "housekeeping" serum miRNA/small RNA), as other classes of RNAs or mRNAs are not stable in serum? Apart from these issues, questions about the biological half-life of the circulating miRs need to be addressed, as this has critical effects in clinical applications. Therefore, the functional roles of miRNAs in tumor biology are currently being unraveled and worth further investigations.

\section{References}

1. Etzioni, R.; Urban, N.; Ramsey, S.; McIntosh, M.; Schwartz, S.; Reid, B.; Radich, J.; Anderson, G.; Hartwell, L. The case for early detection. Nat. Rev. Cancer 2003, 3, 243-252.

2. Schetter, A.J.; Harris, C.C. Plasma microRNAs: a potential biomarker for colorectal cancer? Gut 2009, 58, 1318-1319.

3. Calin, G.A.; Croce C.M. MicroRNA signatures in human cancers. Nat. Rev. Cancer 2006, 6, 857-866.

4. Cho, W.C. Molecular diagnostics for monitoring and predicting therapeutic effect in cancer. Expert Rev. Mol. Diagn. 2011, 11, 9-12.

5. Griffiths-Jones, S.; Saini, H.K.; van Dongen, S.; Enright, A.J. miRBase: Tools for microRNA genomics. Nucleic Acids Res. 2008, 36, D154-D158.

6. Esquela-Kerscher, A.; Slack, F.J. Oncomirs-microRNAs with a role in cancer. Nat. Rev. Cancer 2006, 6, 259-269.

7. Calin, G.A.; Sevignani, C.; Dumitru, C.D.; Hyslop, T.; Noch, E.; Yendamuri, S.; Shimizu, M.; Rattan, S.; Bullrich, F.; Negrini, M.; Croce, C.M. Human microRNA genes are frequently located at fragile sites and genomic regions involved in cancers. Proc. Natl. Acad. Sci. USA 2004, 101, 2999-3004.

8. Garzon, R.; Calin, G.A.; Croce, C.M. MicroRNAs in Cancer. Annu. Rev. Med. 2009, 60, 167-179.

9. Landi, M.T.; Zhao, Y.; Rotunno, M.; Koshiol, J.; Liu, H.; Bergen, A.W.; Rubagotti, M.; Goldstein, A.M.; Linnoila, I.; Marincola, F.M.; et al. MicroRNA expression differentiates histology and predicts survival of lung cancer. Clin. Cancer Res. 2010, 16, 430-441. 
10. Cimmino, A.; Calin, G.A.; Fabbri, M.; Iorio, M.V.; Ferracin, M.; Shimizu, M.; Wojcik, S,E.; Aqeilan, R.I.; Zupo, S.; Dono, M.; et al. miR-15 and miR-16 induce apoptosis by targeting BCL2. Proc. Natl. Acad. Sci. USA 2005, 102, 13944-13949.

11. Guo, J.; Miao, Y.; Xiao, B.; Huan, R.; Jiang, Z.; Meng, D.; Wang, Y. Differential expression of microRNA species in human gastric cancer versus non-tumorous tissues. $J$ Gastroenterol. Hepatol. 2009, 24, 652-657.

12. Asaga, S.; Kuo, C.; Nguyen, T.; Terpenning, M.; Giuliano, A.E.; Hoon, D.S. Direct serum assay for microRNA-21 concentrations in early and advanced breast cancer. Clin. Chem. 2011, 57, 84-91.

13. Cho, W.C. MicroRNAs in cancer-from research to therapy. Biochim. Biophys. Acta 2010, 1805, 209-217.

14. Cho, W.C. MicroRNAs: Potential biomarkers for cancer diagnosis, prognosis and targets for therapy. Int. J. Biochem. Cell Biol. 2010, 42, 1273-1281.

15. Lu, J.; Getz, G.; Miska, E.A.; Alvarez-Saavedra, E.; Lamb, J.; Peck, D.; Sweet-Cordero, A.; Ebert, B.L.; Mak, R.H.; Ferrando, A.A.; et al. MicroRNA expression profiles classify human cancers. Nature 2005, 435, 834-838.

16. Segura, M.F.; Belitskaya-Lévy, I.; Rose, A.E.; Zakrzewski, J.; Gaziel, A.; Hanniford, D.; Darvishian, F.; Berman, R.S.; Shapiro, R.L.; Pavlick, A.C.; et al. Melanoma MicroRNA signature predicts post-recurrence survival. Clin. Cancer Res. 2010, 16, 1577-1586.

17. Yu, S.L.; Chen, H.Y.; Chang, G.C.; Chen, C.Y.; Chen, H.W.; Singh, S.; Cheng, C.L.; Yu, C.J.; Lee, Y.C.; Chen, H.S.; et al. MicroRNA signature predicts survival and relapse in lung cancer. Cancer Cell 2008, 13, 48-57.

18. Mitchell, P.S.; Parkin, R.K.; Kroh, E.M.; Fritz, B.R.; Wyman, S.K.; Pogosova-Agadjanyan, E.L.; Peterson, A.; Noteboom, J.; O'Briant, K.C.; Allen, A.; et al. Circulating microRNAs as stable blood-based markers for cancer detection. Proc. Natl. Acad. Sci. USA 2008, 105, 10513-10518.

19. Chen, X.; Ba, Y.; Ma, L.; Cai, X.; Yin, Y.; Wang, K.; Guo, J.; Zhang, Y.; Chen, J.; Guo, X.; et al. Characterization of microRNAs in serum: a novel class of biomarkers for diagnosis of cancer and other diseases. Cell Res. 2008, 18, 997-1006.

20. Li, J.; Smyth, P.; Flavin, R.; Cahill, S.; Denning, K.; Aherne, S.; Guenther, S.M.; O'Leary, J.J.; Sheils, O. Comparison of miRNA expression patterns using total RNA extracted from matched samples of formalin-fixed paraffin-embedded (FFPE) cells and snap-frozen cells. BMC Biotechnol. 2007, 7, 36.

21. Wong, T.S.; Liu, X.B.; Wong, B.Y.; Ng, R.W.; Yuen, A.P.; Wei, W.I. Mature miR-184 as potential oncogenic microRNA of squamous cell carcinoma of tongue. Clin. Cancer Res 2008, 14, 2588-2592.

22. Valadi, H.; Ekström, K.; Bossios, A.; Sjöstrand, M.; Lee, J.J.; Lötvall, J.O. Exosome-mediated transfer of mRNAs and microRNAs is a novel mechanism of genetic exchange between cells. Nat. Cell Biol. 2007, 9, 654-659.

23. Kosaka, N.; Iguchi, H.; Yoshioka, Y.; Takeshita, F.; Matsuki, Y.; Ochiya, T.; Secretory mechanisms and intercellular transfer of microRNAs in living cells. J. Biol. Chem. 2010, 285, 17442-17452.

24. Rabinowits, G.; Gerçel-Taylor, C.; Day, J.M.; Taylor, D.D.; Kloecker, G.H. Exosomal microRNA: A diagnostic marker for lung cancer. Clin. Lung Cancer 2009, 10, 42-46. 
25. Li, A.; Omura, N.; Hong, S.M.; Vincent, A.; Walter, K.; Griffith, M.; Borges, M.; Goggins, M. Pancreatic cancers epigenetically silence SIP1 and hypomethylate and overexpress miR-200a/200b in association with elevated circulating miR-200a and miR-200b levels. Cancer Res. 2010, 70, 5226-5237.

26. Tsujiura, M.; Ichikawa, D.; Komatsu, S.; Shiozaki, A.; Takeshita, H.; Kosuga, T.; Konishi, H.; Morimura, R.; Deguchi, K.; Fujiwara, H.; Okamoto, K.; Otsuji, E. Circulating microRNAs in plasma of patients with gastric cancers. Br. J. Cancer. 2010, 102, 1174-1179.

27. Heneghan, H.M.; Miller, N.; Lowery, A.J.; Sweeney, K.J.; Newell, J.; Kerin, M.J. Circulating microRNAs as novel minimally invasive biomarkers for breast cancer. Ann. Surg. 2010, 251, 499-505.

28. Shigoka, M.; Tsuchida, A.; Matsudo, T.; Nagakawa, Y.; Saito, H.; Suzuki, Y.; Aoki, T.; Murakami, Y.; Toyoda, H.; Kumada, T. Deregulation of miR-92a expression is implicated in hepatocellular carcinoma development. Pathol. Int. 2010, 60, 351-357.

29. Calin, G.A.; Liu, C.G.; Sevignani, C.; Ferracin, M.; Felli, N.; Dumitru, C.D.; Shimizu, M.; Cimmino, A.; Zupo, S.; Dono, M. MicroRNA profiling reveals distinct signatures in B cell chronic lymphocytic leukemias. Proc. Natl. Acad. Sci. USA 2004, 101, 11755-11760.

30. Lawrie, C.H.; Gal, S.; Dunlop, H.M.; Pushkaran, B.; Liggins, A.P.; Pulford, K.; Banham, A.H.; Pezzella, F.; Boultwood, J.; Wainscoat, J.S.; Hatton, C.S.; Harris, A.L. Detection of elevated levels of tumour-associated microRNAs in serum of patients with diffuse large B-cell lymphoma. Br. J. Haematol. 2008, 141, 672-675.

31. Leidinger, P.; Keller, A.; Borries, A.; Reichrath, J.; Rass, K.; Jager, S.U.; Lenhof, H.P.; Meese, E. High-throughput miRNA profiling of human melanoma blood samples. BMC Cancer 2010, 10, 262.

32. Hu, Z.; Chen, X.; Zhao, Y.; Tian, T.; Jin, G.; Shu, Y.; Chen, Y.; Xu, L.; Zen, K.; Zhang, C.; et al. Serum microRNA signatures identified in a genome-wide serum microRNA expression profiling predict survival of non-small-cell lung cancer. J. Clin. Oncol. 2010, 28, 1721-1726.

33. Wang, F.; Zheng, Z.; Guo, J.; Ding, X. Correlation and quantitation of microRNA aberrant expression in tissues and sera from patients with breast tumor. Gynecol Oncol. 2010, 119, 586-593.

34. Ng, E.K.; Chong, W.W.; Jin, H.; Lam, E.K.; Shin, V.Y.; Yu, J.; Poon, T.C.; Ng, S.S.; Sung, J.J. Differential expression of microRNAs in plasma of patients with colorectal cancer: a potential marker for colorectal cancer screening. Gut 2009, 58, 1375-1381.

35. Huang, Z.; Huang, D.; Ni, S.; Peng, Z.; Sheng, W.; Du, X. Plasma microRNAs are promising novel biomarkers for early detection of colorectal cancer. Int. J. Cancer 2010, 127, 118-126.

36. Liu, R.; Zhang, C.; Hu, Z.; Li, G.; Wang, C.; Yang, C.; Huang, D.; Chen, X.; Zhang, H.; Zhuang, R.; et al. A five-microRNA signature identified from genome-wide serum microRNA expression profiling serves as a fingerprint for gastric cancer diagnosis. Eur. J. Cancer 2010, 9, 26.

37. Yamamoto, Y.; Kosaka, N.; Tanaka, M.; Koizumi, F.; Kanai, Y.; Mizutani, T.; Murakami, Y.; Kuroda, M.; Miyajima, A.; Kato, T.; et al. MicroRNA-500 as a potential diagnostic marker for hepatocellular carcinoma. Biomarkers 2009, 14, 529-538.

38. Li, L.M.; Hu, Z.B.; Zhou, Z.X.; Chen, X.; Liu, F.Y.; Zhang, J.F.; Shen, H.B.; Zhang, C.Y.; Zen, K. Serum microRNA profiles serve as novel biomarkers for HBV infection and diagnosis of HBV-positive hepatocarcinoma. Cancer Res. 2010, 70, 9798-9807. 
39. Tanaka, M.; Oikawa, K.; Takanashi, M.; Kudo, M.; Ohyashiki, J.; Ohyashiki, K.; Kuroda, M. Down-regulation of miR-92 in human plasma is a novel marker for acute leukemia patients. PLoS One 2009, 4, e5532.

40. Moussay, E.; Palissot, V.; Vallar, L.; Poirel, H.A.; Wenner, T.; El Khoury, V.; Aouali, N.; van Moer, K.; Leners, B.; Bernardin, F.; et al. Determination of genes and microRNAs involved in the resistance to fludarabine in vivo in chronic lymphocytic leukemia. Mol. Cancer 2010, 20, 115.

41. Unno, K.; Zhou, Y.; Zimmerman, T.; Platanias, L.C.; Wickrema, A. Identification of a novel microRNA cluster miR-193b-365 in multiple myeloma. Leuk. Lymphoma 2009, 50, 1865-1871.

42. Liu, C.J.; Kao, S.Y.; Tu, H.F.; Tsai, M.M.; Chang, K.W.; Lin, S.C. Increase of microRNA miR-31 level in plasma could be a potential marker of oral cancer. Oral Dis. 2010, 16, 360-364.

43. Resnick, K.E.; Alder, H.; Hagan, J.P.; Richardson, D.L.; Croce, C.M.; Cohn, D.E. The detection of differentially expressed microRNAs from the serum of ovarian cancer patients using a novel real-time PCR platform. Gynecol. Oncol. 2009, 112, 55-59.

44. Häusler, S.F.; Keller, A.; Chandran, P.A.; Ziegler, K.; Zipp, K.; Heuer, S.; Krockenberger, M.; Engel, J.B.; Hönig, A.; Scheffler, M.; et al. Whole blood-derived miRNA profiles as potential new tools for ovarian cancer screening. Br. J. Cancer 2010, 103, 693-700.

45. Taylor, D.D.; Gercel-Taylor, C. MicroRNA signatures of tumor-derived exosomes as diagnostic biomarkers of ovarian cancer. Gynecol. Oncol. 2008, 110, 13-21.

46. Wang, J.; Chen, J.; Chang, P.; LeBlanc, A.; Li, D.; Abbruzzesse, J.L.; Frazier, M.L.; Killary, A.M.; Sen, S. MicroRNAs in plasma of pancreatic ductal adenocarcinoma patients as novel blood-based biomarkers of disease. Cancer Prev. Res. (Phila Pa) 2009, 2, 807-813.

47. Ho, A.S.; Huang, X.; Cao, H.; Christman-Skieller, C.; Bennewith, K.; Le, Q.T.; Koong, A.C. Circulating, miR-210 as a novel hypoxia marker in pancreatic cancer. Transl. Oncol. 2010, 3, 109-113.

48. Ali, S.; Almhanna, K.; Chen, W.; Philip, P.A.; Sarkar, F.H. Differentially expressed miRNAs in the plasma may provide a molecular signature for aggressive pancreatic cancer. Am. J. Transl. Res. 2010, 3, 28-47.

49. Zhang, C.; Wang, C.; Chen, X.; Yang, C.; Li, K.; Wang, J.; Dai, J.; Hu, Z.; Zhou, X.; Chen, L.; et al. Expression profile of microRNAs in serum: a fingerprint for esophageal squamous cell carcinoma. Clin. Chem. 2010, 56, 1871-1879.

50. Miyachi, M.; Tsuchiya, K.; Yoshida, H.; Yagyu, S.; Kikuchi, K.; Misawa, A.; Iehara, T.; Hosoi, H. Circulating muscle-specific microRNA, miR-206, as a potential diagnostic marker for rhabdomyosarcoma. Biochem. Biophys. Res. Commun. 2010, 400, 89-93.

51. Brase, J.C.; Wuttig, D.; Kuner, R.; Sültmann, H. Serum microRNAs as non-invasive biomarkers for cancer. Mol. Cancer 2010, 26, 306.

(C) 2011 by the authors; licensee MDPI, Basel, Switzerland. This article is an open access article distributed under the terms and conditions of the Creative Commons Attribution license (http://creativecommons.org/licenses/by/3.0/). 